\title{
The illegal pet trade is driving Madagascar's ploughshare tortoise to extinction
}

\author{
Angelo R. Mandimbihasina, Lance G. Woolater, Lianne E. Concannon \\ E. J. Milner-Gulland, Richard E. Lewis, Andrew M.R. Terry \\ Niaraha Filazaha, Lydia L. Rabetafika and Richard P. Young
}

\begin{abstract}
The illegal wildlife trade is driving declines in populations of a number of large, charismatic animal species but also many lesser known and restricted-range species, some of which are now facing extinction as a result. The ploughshare tortoise Astrochelys yniphora, endemic to the Baly Bay National Park of north-western Madagascar, is affected by poaching for the international illegal pet trade. To quantify this, we estimated population trends during 2006-2015, using distance sampling surveys along line transects, and recorded national and international confiscations of trafficked tortoises for 2002-2016. The results suggest the ploughshare tortoise population declined $>50 \%$ during this period, to c. 500 adults and subadults in 2014-2015. Prior to 2006 very few tortoises were seized either in Madagascar or internationally but confiscations increased sharply from 2010. Since 2015 poaching has intensified, with field reports suggesting that two of the four subpopulations are extinct, leaving an unknown but almost certainly perilously low number of adult tortoises in the wild. This study has produced the first reliable population estimate of the ploughshare tortoise and shows that the species has declined rapidly because of poaching for the international pet trade. There is an urgent need for increased action both in Madagascar and along international trade routes if the extinction of the ploughshare tortoise in the wild is to be prevented.
\end{abstract}

Keywords Anti-poaching, Astrochelys yniphora, chelonian, distance sampling, illegal wildlife trade, line transect surveys, ploughshare tortoise, population monitoring

Angelo Mandimbihasina* (Corresponding author), Lance Woolaver, Richard E. Lewis and Niaraha Filazaha Durrell Wildlife Conservation Trust, Lot IIY 49 J Ampasanimalo, BP 8511, 101 Antananarivo, Madagascar E-mail angelo.ramy@durrell.org

Lianne Concannon, Andrew R. M. Terry and Richard Young Durrell Wildlife Conservation Trust, Trinity, Jersey, Channel Islands

E. J. Milner-GulLand Department of Zoology, University of Oxford, Oxford, UK

Lydia L. Rabetafika Department of Animal Biology, Faculty of Sciences, University of Antananarivo, Antananarivo, Madagascar

${ }^{*}$ Also at: Department of Animal Biology, University of Antananarivo, Antananarivo, Madagascar

Received 27 September 2017. Revision requested 21 November 2017. Accepted 1 December 2017. First published online 7 September 2018.

\section{Introduction}

Tlegal wildlife trade involves the collection, transporta1 tion, and distribution of living or dead animals, animal parts and derivatives, both domestically and internationally, in contravention of foreign and domestic laws and treaties (Wyler \& Sheikh, 2013). It is a major and growing challenge for conservation. Although the global volume of illegal wildlife trade is difficult to quantify (Rosen \& Smith, 2010), its value is estimated at USD 8-10 billion per annum (Lawson \& Vines, 2014). Illegal trade is pushing many highprofile species such as the tiger Panthera tigris, African elephant Loxodonta africana, and white and black rhinoceroses Diceros bicornis and Ceratotherium simum, towards extinction (Bennett, 2011; Biggs et al., 2013; Underwood et al., 2013; TRAFFIC, 2016).

Illegal trade also affects a wide range of lesser-known species (Rosen \& Smith, 2010) that often receive little international attention. Reptiles, and chelonians in particular, are trafficked in large numbers, accounting for 69 and $38 \%$, respectively, of total seizures of live animals recorded in TRAFFIC Bulletins during 1996-2008 (Rosen \& Smith, 2010). Collection of reptiles for illegal trade is rarely sustainable and causes declines in wild populations (Zhou \& Jiang, 2004; Natusch \& Lyons, 2012; Nijman et al., 2012), with turtles and tortoises being affected heavily (Jenkins, 1995; Cheung \& Dudgeon, 2006; Horne et al., 2012). Linked to traditional rites, beliefs, food preferences and medicinal uses, tortoises have been trafficked primarily into South-east and eastern Asia, with a high number of exports originating from Africa (Jenkins, 1995; Nijman \& Shepherd, 2007, 2015).

All four of Madagascar's endemic tortoise species, the radiated tortoise Astrochelys radiata, ploughshare tortoise Astrochelys yniphora, spider tortoise Pyxis arachnoides and flat-tailed tortoise Pyxis planicauda, are listed on Appendix I of CITES (2017) and categorized as Critically Endangered on the IUCN Red List (Leuteritz et al., 2008; Leuteritz \& Pedrono, 2008; Leuteritz \& Rioux Paquette, 2008; Leuteritz \& Walker, 2014). All have been, or are currently, affected by illegal collection from the wild for the international pet trade (O'Brien et al., 2003; Pedrono, 2008; Walker \& Rafeliarisoa, 2012).

The ploughshare tortoise has long been considered one of the world's rarest tortoises (Juvik \& Blanc, 1974; Curl et al., 1985), perhaps in part because of a long history of 
exploitation. Vaillant \& Grandidier (1910) describe a naval archive from the 17th century which notes that stores in the region were full of tortoises, many of which were purchased by Arab sailors. Although historically ploughshare tortoises were exploited for food, demand has shifted in the latter part of the 2oth century to keeping them as pets, primarily in South-east Asia (Kiester et al., 2013; Raghavan et al., 2015). The ploughshare tortoise has been protected by Malagasy law since 1960 (the law was revised in 2006), which prohibits collection from the wild, transportation, keeping in captivity as pets, consumption, sale or export of live individuals.

Currently found only in the bamboo scrub habitats around Baly Bay on the north-western coast of Madagascar, there is no evidence from the historical or sub-fossil record to suggest that the species was ever found outside of this highly restricted locality. All known ploughshare habitats are now legally protected as core zones of Baly Bay National Park (Fig. 1), established in 1997. All entry, except for conservation and research purposes, is forbidden.

A number of ploughshare tortoise population surveys have been carried out. In the mid 1980s the population was estimated to be 100-400 individuals (Curl, 1986) and an estimate of $605 \pm 166$ individuals was reported in 2000 (Pedrono, 2000). The survey methods used to produce these estimates did not account for biases arising from imperfect detection, nor did they cover the species' full range; consequently there is no reliable information on historical or current population sizes.

A significant decline in numbers of the ploughshare tortoise is suspected to have occurred during 2000-2005, but this has not been quantified. Here we present the results of surveys conducted during 2006-2015 covering the entire species range, with the first robust estimates of ploughshare tortoise population size and trend. We report data from anti-poaching patrols conducted since 2015 to understand more recent population changes and also examine data from seizures of ploughshare tortoises over the same 10-year period as an indicator of the level of trafficking of this species.

\section{Study area}

We carried out line transect surveys at Ambatomainty, Betainalika, Beheta and Cap Sada, the four known sites supporting extant ploughshare tortoise subpopulations within the Baly Bay National Park (Fig. 1). There is also a reintroduction site at Beaboaly, where a known number of released tortoises are intensively monitored. The Park is located around Baly Bay in the Region of Boeny on the northwestern coast of Madagascar. This region has two distinct seasons: a rainy, hot period December-March, and a dry, cooler season April-November. The former coincides with the ploughshare's active season during which breeding occurs and the latter with a long period of low activity and aestivation.

Ploughshare tortoise habitat comprises dense patches of bamboo thicket Perrierbambus madagascariensis, scrubshrub, and palm savannah (Smith et al., 1999a), with bamboo thicket being the least accessible and most difficult to survey (Juvik et al., 1981). The suitable habitat patches are isolated, separated from each other by grass savannahs, seasonal rivers, lakes, mangroves, marshes, salt marshes and the Bay of Baly (Fig. 1). Two patches of habitat, Cap Sada (235 ha) and Beheta (688 ha) are located on the eastern side of the bay and two, Betainalika (2,905 ha) and Ambatomainty (10,645 ha), on the western side (Mandimbihasina \& Woolaver, 2014).

\section{Methods}

Line transect population surveys and analyses

Distance sampling (Buckland et al., 2001) is widely used for monitoring land tortoises (Swann et al., 2002; Leuteritz et al., 2005; Young et al., 2008; Smith et al., 2009; Walker \& Rafeliarisoa, 2012) and has been carried out by Durrell Wildlife Conservation Trust periodically since 2005 (with a pilot study in 2003-2004) to estimate ploughshare tortoise densities. Line transects were surveyed in October-April in 2006-2008, 2011-2013 and 2014-2015, between 08.00-11.00 and 15.00-17.00, because tortoises were more active during these cooler hours. For a given transect, a team of 3-11 surveyors walked in parallel lines $10 \mathrm{~m}$ apart, with a team leader in the middle responsible for navigating and measuring the length of the transect. The survey team consisted of a professional biologist acting as team leader and trained members of the local community. All team members walked along the line transect at the same speed of $0.5-0.7 \mathrm{~km} / \mathrm{h}$ and in the same direction (either east-west or northsouth). The leader and the surveyors at the ends of the line used global positioning system (GPS) units to record the travel distance and ensure the walked lines were as straight as possible. The transect length was then calculated as the distance walked by the survey team multiplied by the number of people in that team.

For each survey session $0.6-1.6 \mathrm{~km}$ long line transects were randomly placed at least $500 \mathrm{~m}$ apart to cover all four sites of ploughshare tortoise habitat. One area of c. $50 \mathrm{~km}^{2}$ in the centre of the largest site of tortoise habitat in Ambatomainty was too difficult to access and remained unsampled. Eighty-eight transects with a total length of $563.9 \mathrm{~km}$ were surveyed in 2006-2008, $514.2 \mathrm{~km}$ (82 transects) in 2011-2013, and $552.1 \mathrm{~km}$ (72 transects) in 2014-2015.

When a tortoise was found, all observers stopped surveying while data were recorded. The perpendicular distance 


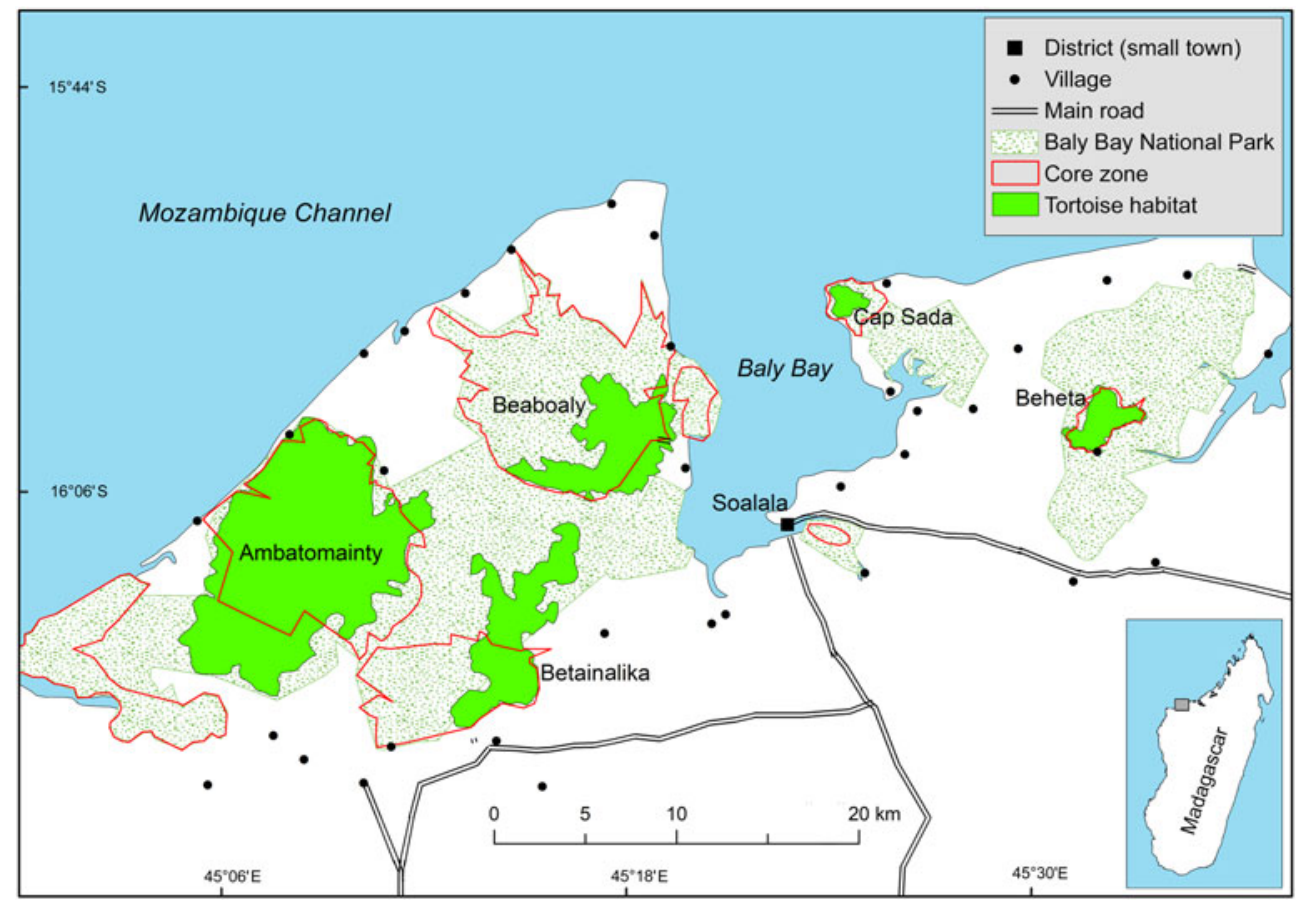

Fig. 1 Map of Baly Bay National Park, Madagascar, showing the strict conservation zones of the National Park and sites of suitable habitat for ploughshare tortoises Astrochelys yniphora. The Ambatomainty, Beheta, Betainalika and Cap Sada sites were surveyed in three survey periods: 2006-2008, 2011-2013 and 2014-2015.

from the tortoise to the line of the surveyor that found it was measured. Sex of adults (based on plastron curvature and anal fork opening), identification number of previously marked animals, and body measurements were recorded for each tortoise. Individuals were assigned to one of two age categories based on their size: adult or subadult if they had a carapace length $>20 \mathrm{~cm}$, and juvenile if $<20 \mathrm{~cm}$. It was not possible to distinguish between the sexes of juveniles during field surveys because this is only possible with endoscopy.

The accuracy of this transect methodology was tested during a pilot study in Cap Sada in 2003-2004. Cap Sada is the best studied of the wild subpopulations of the ploughshare tortoise, with research carried out at this site since the 1970 (e.g. Juvik \& Blanc, 1974; Juvik et al., 1981; Smith et al., 1999b). Nearly all adult and subadult tortoises in Cap Sada had been permanently marked by 2003 and their total number was known. Twenty-seven transects with a total length of $90.2 \mathrm{~km}$, arranged in a systematic grid to ensure good coverage of the entire area of suitable habitat, were surveyed in 2003-2004 and the results were compared to the known population size of adults in the subpopulation.

In an attempt to understand the status of the ploughshare tortoise population since 2015, we collated data on any tortoises observed in the wild during anti-poaching patrols conducted in Baly Bay National Park. The patrols covered the sites of all four wild subpopulations and the reintroduced subpopulation, searching for signs of poaching activity (e.g. illegal camps, campfires, paths) and recording numbers and locations of any ploughshare tortoises seen. Patrol teams carried GPS units to measure distances walked and recorded start and finish times of their daily patrols. We calculated the effort (distance walked and time spent patrolling) of the anti-poaching patrols conducted during January 2016-May 2017 and the encounter rates (tortoises encountered per $\mathrm{km}$ walked). Data analyses were carried out using Distance v. 6.2 (Thomas et al., 2010).

Although population size was estimated at the subpopulation level, here we report global population estimates to avoid providing traffickers with information about tortoise numbers at each site that could influence poaching. For both the Cap Sada pilot study and the wider survey the data were truncated to exclude the $5 \%$ of distances furthest from the transect line, to discard unusual observations (Thomas et al., 2010). Based on lowest Akaike Information Criterion (AIC) values and visual inspection of the detection functions, we selected the half-normal cosine model for density estimation in both cases.

\section{National and international confiscation data}

We collated records of ploughshare tortoises seized by authorities outside Madagascar as reported in TRAFFIC Bulletins from June 1998-December 2016 (TRAFFIC, 2014), and accessed from the TRAFFIC website. The age 
of seized tortoises was not always reported, so we recorded only the number of individuals confiscated. Numbers of juveniles and adults were known for all confiscations in Madagascar, so these were used to explore which age classes were most targeted by poachers. We also collated all available anecdotal and reported evidence of trafficking, sales and demand, to examine the dynamics of illegal trade of ploughshare tortoises.

\section{Results}

\section{Tortoise population trends}

In our Cap Sada pilot study in 2003-2004 we observed 14 adults along 27 transect lines totalling $90.2 \mathrm{~km}$. Despite the small sample size, the detection function provided a good fit to the data $\left(\chi^{2}=3.81, \mathrm{P}=0.43\right)$ and we estimated a density of 0.19 adult tortoises per ha $(95 \% \mathrm{CI}=0.11-0.33$ adult tortoises per ha) and a population size of 34 individuals ( $95 \% \mathrm{CI}=20-58$ tortoises). This is relatively close to the 41 adults believed to be in the subpopulation at the time based on data from the long-term mark-recapture study (Smith et al., 1999b) of 1993-2004.

Despite a survey effort of $>500 \mathrm{~km}$ per survey session, totalling $1720.4 \mathrm{~km}$ of line transects over the 10-year monitoring period, we did not meet the target number of tortoise observations required (6o-8o data points per period; Buckland et al., 2001) to reliably model a detection function for each of the three sampling periods. Therefore the data were pooled to estimate a global detection function (i.e. applied to all three survey periods; Obbard et al., 2015), which showed no signs of avoidance of the survey line or heaping of observations at any distance, which was post-stratified to generate population abundance and density estimates for each survey period. The detection function provided a good fit to the data $\left(\chi^{2}=10.76, \mathrm{df}=11, \mathrm{P}=0.46\right)$, and was used to estimate density because it had the lowest AIC value across all possible models.

Ploughshare tortoise encounter rates and population density and size estimates for each survey session are presented in Table 1 . The confidence intervals around the mean estimated population sizes are large, but the difference in the mean estimates suggest a rapid decline in wild ploughshare tortoises between 2006-2008 and 2011-2013, and a negligible difference between 2011-2013 and 20142015. The overall decline in the mean population estimates over the 10 -year period is $54 \%$.

However, reports from anti-poaching patrols and conservation NGO field teams during January 2016-May 2017 suggest the situation has deteriorated further. Multiple visits by both groups during this period covered all four main sites of suitable habitat, plus the reintroduction site, in both the active and low activity seasons. Quality-controlled data of patrol effort were only available for Beaboaly, where the joint anti-poaching teams conducted 6,019 hours of patrolling covering $3,815 \mathrm{~km}$ to protect the reintroduced population. For the other four sub-populations, patrols totalled 14,400 hours. This at least equals the effort (in terms of time spent searching for tortoises and surface area covered) of conducting the $1,700 \mathrm{~km}$ of surveys during 2006-2015. Despite this large-scale and intensive search effort, no animals have been seen in two of the wild subpopulations since the end of 2016. The situation is less clear for the other two subpopulations, but given the low encounter rates that were observed, we suspect that both have been severely depleted since 2015 and (based on only one individual being found) one subpopulation now consists of $<10$ individuals.

\section{Trends in confiscations}

The first report of ploughshare tortoises confiscated outside Madagascar was of three individuals seized in Belgium in 1998. The next was one individual confiscated in Japan in 2004. The number seized per year outside Madagascar has increased since 2006 (Fig. 2) with peaks in 2010 (39 tortoises) and 2013 (58). A total of 162 ploughshare tortoises have been confiscated outside Madagascar in 35 separate seizures during 2002-2016 (Fig. 2).

The first confiscation recorded in Madagascar was in 2002, of nine adults in a single seizure, and only a single juvenile was confiscated during the following 3 -year period up to 2005 . However, since 2006 the number of confiscated ploughshare tortoises in Madagascar has increased each year (Fig. 2) with peaks in 2011 (54 tortoises) and 2014 (28). The total number of ploughshare tortoises confiscated within Madagascar during 2002-2016 was 172 individuals

TABLE 1 Number of ploughshare tortoises recorded (A, adults; SA, subadults; J, juveniles) during surveys, encounter rates, and population density and size estimates with lower and upper $95 \%$ confidence limits (CL).

\begin{tabular}{lllllrlr}
\hline Time period & $\begin{array}{l}\text { Distance } \\
\text { surveyed }(\mathrm{km})\end{array}$ & $\begin{array}{l}\text { Tortoises recorded } \\
\text { A + SA/J }\end{array}$ & $\begin{array}{l}\text { Encounter rate A+SA/J } \\
\text { (tortoises per km) }\end{array}$ & $\begin{array}{l}\text { Density } \\
\text { (tortoises per ha) }\end{array}$ & $\begin{array}{l}\text { Population } \\
\text { size }\end{array}$ & $\begin{array}{l}\text { Lower } \\
\text { 95\% CL }\end{array}$ & $\begin{array}{l}\text { Upper } \\
95 \% \text { CL }\end{array}$ \\
\hline $2006-2008$ & 563.9 & $43 / 15$ & $0.076 / 0.027$ & 0.076 & 1,105 & 709 & 1,722 \\
$2011-2013$ & 514.2 & $26 / 18$ & $0.056 / 0.035$ & 0.036 & 517 & 174 & 1,535 \\
$2014-2015$ & 552.1 & $38 / 13$ & $0.067 / 0.024$ & 0.035 & 506 & 188 & 1,359 \\
\hline
\end{tabular}

${ }^{\star}$ Population density and size estimates are for adults and subadults only. 


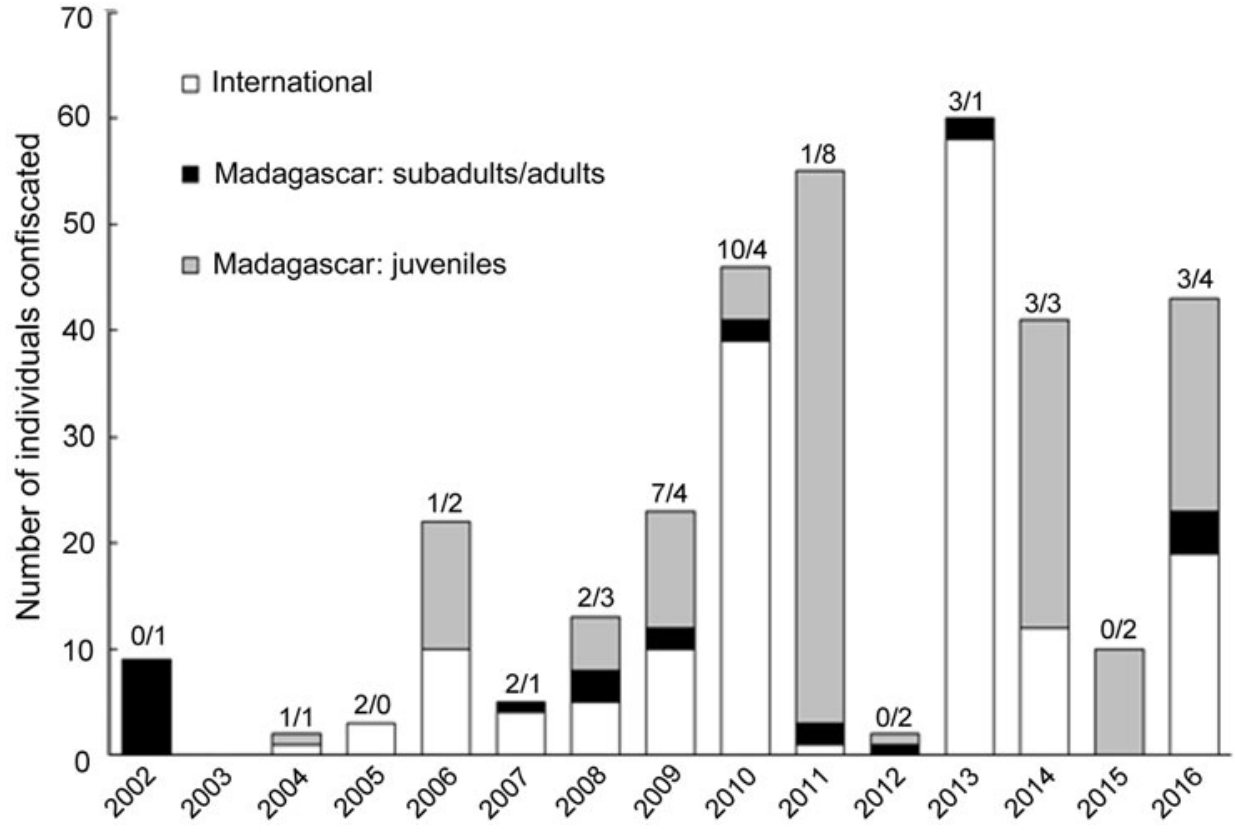

FIG. 2 Number of ploughshare tortoises confiscated internationally and in Madagascar in 2002-2016 (age-specific data were only available for national confiscations). Numbers above each column indicate number of seizures (international/ Madagascar) for that year. Juveniles were defined as tortoises with a carapace length $<20 \mathrm{~cm}$.
(26 adults and 146 juveniles) in 36 seizures. The total number of seizures (international and national) was highest in 2009-2011 (11, 14, 9 seizures, respectively) and 2016 (7), compared with $0-4$ seizures in all other years.

\section{Additional evidence of illegal wildlife trade}

During the period of rapid population decline, NGO field teams in Baly Bay observed an escalation in the reported price being offered to local poachers by collectors for an adult ploughshare tortoise, from c. USD 2 in 2009, to USD 62 in 2015 and USD 620 in 2016 (Jinoro Delphin, pers. comm.). For context, the mean local wage in the villages adjacent to the National Park is USD 1.5-2 per day (Andrianandrasana, 2017).

The main intended destinations for ploughshare tortoises, based on confiscation patterns, are Thailand, Malaysia, Singapore, Indonesia and Hong Kong, with animals transiting through Kenya and Abu Dhabi from Madagascar (TRAFFIC, 2014). Although data are lacking on trade routes into China, it is suspected that many trafficked animals are destined for collectors there (Gibbons, 2015). Collectors in demand countries pay high prices for ploughshare tortoises, with recent reports of tortoises for sale in Indonesia from USD 509 for a small individual to USD 47,00o for a large animal (Morgan \& Chng, 2017).

Use of the internet and social media platforms appears to facilitate illegal trade of ploughshare tortoises (Morgan \& Chng, 2017), which first started appearing for sale online in c. 2008 (Walker, 2012; Kiester et al., 2013). We suspect there has been a recent spike in online sales, e.g. five adult ploughshare tortoises were on sale on a Hong Kong website in 2015, and seven were for sale online in 2016 (R. Lewis, pers. comm.). Nine of these were confirmed as having recently been taken from wild populations, based on identification markings visible in the online photographs.

\section{Discussion}

Our study provides the first estimates of ploughshare tortoise population size and trend based on range-wide surveys, using a method that takes imperfect detection into account. Our results reveal that the ploughshare tortoise probably declined by $>50 \%$ during 2006-2015, but more recent field patrols suggest an even larger decline, with some subpopulations (at least the adults and subadults) now probably extinct. Concurrent data on escalating confiscations in Madagascar and South-east Asia, together with anecdotal evidence of high and increasing levels of poaching activity in Baly Bay, identify the illegal international pet trade as the driver of this rapid and severe decline.

Given the low population density of this species, over $1,700 \mathrm{~km}$ of survey effort was required to obtain sufficient sample sizes for analyses. The remoteness and relative inaccessibility of the study area, combined with the cryptic nature of the species and its short active season, resulted in several limitations of the survey. Firstly, because of lower than anticipated numbers of tortoise detections, our population estimates had relatively wide confidence intervals (although our pilot study of the line transect method to survey the Cap Sada population produced a population estimate close to the known population size, despite the low numbers of observations). Secondly, we were not able to access the central portion of Ambatomainty, the western-most and largest patch of suitable habitat, because of its remoteness and dense vegetation. In the analysis, we assumed tortoise 


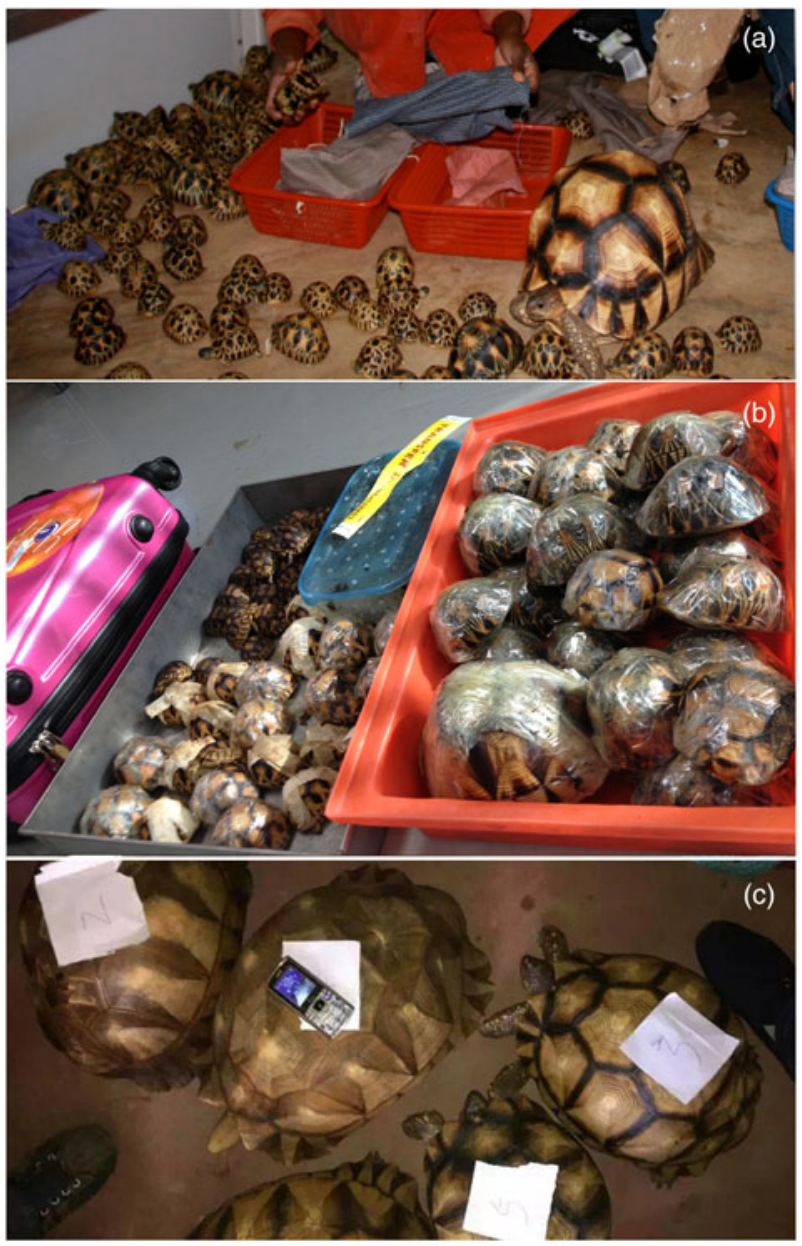

FIG. 3 Photos of the illegal trade in ploughshare tortoises. (a) A shipment confiscated in Madagascar at Ivato International Airport in July 2011 included 27 juvenile and 1 adult ploughshare tortoise, 169 radiated tortoises Astrochelys radiata, and a spider tortoise Pyxis arachnoides (Durrell Wildlife Conservation Trust, 2011). (b) A seizure of Malagasy tortoises in Thailand in 2013 included 54 ploughshare tortoises and 21 radiated tortoises (Panjit Tansome, TRAFFIC 2013). (c) Five adult ploughshare tortoises, two of which are clearly engraved, for sale on a Chinese website in June 2015.

density in this area to be equivalent to the mean density across the rest of the species' range. Given its challenging accessibility, this may be an important site for ploughshare tortoises and requires continued intensive protection. Thirdly, as a result of the low numbers of juveniles observed, we were limited to estimating population size and density for adults and subadults. Smaller individuals are hard to detect in the dense bamboo scrub, but the lack of sightings of juveniles in some subpopulations in 2011-2013 and 20142015, compared with earlier years, suggests a decline in the number of individuals in this age class. Most of the ploughshare tortoises confiscated have been juveniles, which can be more easily concealed and transported in large numbers (Fig. 3), and this could partially explain the lack of sightings of juveniles.
Despite these limitations, we believe the evidence presented here points to a catastrophic decline in the ploughshare tortoise. In 2014-2015 the estimated density of individuals of or near breeding age was only 3.5 individuals per $\mathrm{km}^{2}$. To put this into context, the density (of all age classes) of the rare and threatened Sonoran desert tortoise Gopherus agassizii at an arid mountain site in the southern USA was 30 individuals per $\mathrm{km}^{2}$ (Zylstra et al., 2010). The lack of ploughshare tortoise observations since January 2016, despite repeated field visits, leads us to suspect that only one of the four wild subpopulations contains $>10$ adults and subadults, and two of the subpopulations have probably been extirpated. Given its long generation time of c. 20 years and limited capacity to recover from population declines, this species is now in a perilous situation and its survival is at risk.

At the time of writing, 334 ploughshare tortoises have been confiscated (both within and outside Madagascar) during trafficking attempts since 2002, 280 of these since 2009. Seizure data consistently and substantially underestimate actual numbers of animals poached (D'Cruze \& Macdonald, 2016), and therefore the numbers of adults and juveniles taken from the wild and trafficked since 2009 may be in the low thousands (probably mostly juveniles, which are not represented in our population estimates). Although it is not possible to evaluate temporal trends in enforcement effort, there has been an increase in corruption in Madagascar since the political instability commencing in 2009, leading to a reduced capacity to control illegal trade (Randriamalala \& Liu, 2010; Gore et al., 2013). This corresponds with our survey results, which show a significant drop in numbers between the first and second survey periods, indicating that intensive poaching started c. 2009.

When the ploughshare tortoise population rapidly declined, increasing effort will have been required by poachers to locate tortoises in the wild, which could be a disincentive for poaching. However, the Anthropogenic Allee effect predicts that increasing species rarity drives up desirability, which in turn drives up the amount people are willing to pay (Hall et al., 2008; Lyons \& Natusch, 2013). This is reflected in the 300 -fold increase since 2009 in the local price paid to poachers for tortoises taken from the wild. Given that ploughshare tortoises have been for sale for nearly USD 50,000 in a demand country we anticipate that these local price escalations may continue, sustaining the poaching intensity even as the global wild population of the ploughshare tortoise declines to just a few individuals.

Prior to the recent increase in poaching, the ploughshare tortoise conservation programme had made good progress towards achieving its goals, with successful habitat protection, reduction of threats from fire and cattle encroachment, and a promising reintroduction programme (Durbin et al., 1996; Wallis, 2009; Mandimbihasina \& Woolaver, 2014). 
However, the upsurge in international demand, facilitated by weakening governance and limited law enforcement, resulted in conservation agencies having to adapt and diversify their responses rapidly, to include anti-poaching actions, judicial capacity development and national and international advocacy. It is clear that these interventions have not been sufficient in scale or intensity to reduce poaching. Even engraving the carapaces of all wild, released and captive ploughshare tortoises (John \& Shepherd, 2014) appears to have failed to reduce demand, with engraved animals now for sale online. A lack of enforcement action against traders or buyers of these engraved tortoises has probably contributed to the lack of success of this campaign.

Immediate action is needed to safeguard the remaining wild, released and captive populations. Anti-poaching actions in Baly Bay must be scaled up and improved, including better detection of poachers (e.g. using patrol dogs), tortoise protection (e.g. fences), and rapid response enforcement techniques that have been developed elsewhere to combat poaching (Moreto \& Lemieux, 2015; O’Donoghue \& Rutz, 2015; Avery, 2016). Captive populations are being established outside Madagascar as assurance colonies, using internationally confiscated animals (Kiester et al., 2013), and new breeding centres are also required in Madagascar, with high-security measures to prevent animals being stolen. Strategies to reduce the demand for wild animals should also be considered to secure the long-term future of the species. Demand reduction initiatives for other species, particularly in South-east and East Asia, have had limited success (Challender \& MacMillan, 2014), with little evidence of effectiveness (Olmedo et al., 2017). The consumers driving the trade in this species and other rare reptiles are a relatively small number of dealers and hobbyists, predominantly in eastern Asia, who seek out the rarest animals and for whom the illegality of owning the species appears not to be a deterrent. More research is required to understand the psychology of collectors and to identify the messaging to which this group would be responsive (Veríssimo et al., 2012; Hinsley et al., 2016).

We conclude that the extinction of the ploughshare tortoise in the wild is imminent unless poaching for the illegal pet trade is halted. Even if poaching ceases, we suspect that, given the extent of the demographic collapse of this species, its recovery is unlikely to happen without intensive management such as large-scale reintroductions, and that even with such actions recovery is likely to take decades.

Acknowledgements We thank Madagascar National Parks and Madagascar's Ministry of Ecology, Environment, Forest and Oceans for providing permits and the mandate to carry out this research within Baly Bay National Park. The University of Oxford's Biodiversity Fellows Programme supported AM to analyse and write up the work. We thank those that have helped with the field surveys including local villager patrol members, Baly Bay National Park staff, and local field assistants. Funding for field surveys was provided by the Durrell Wildlife Conservation Trust, Disney Conservation Fund, Turtle Conservation Fund (2013 \& 2014), Turtle Conservancy, and the U.S. Fish \& Wildlife Service's Wildlife Without Borders (EA-0055/2009, EA-0205/2011) -Critically Endangered Animals Conservation Fund.

Author contributions Data collection, data analysis and writing of first draft: AM; help with fieldwork: NF; coordination of field research: LW, REL, LLR; compilation of confiscation data: LW, AM; assistance with data analysis: LC and RY; assistance with writing and editing: LW, LC, EJMG, REL, AT; design lead of field research, writing and editing of later drafts: RY.

\section{Conflicts of interest None.}

Ethical standards The research was authorized by Madagascar National Parks, the manager of Baly Bay National Park, and the Ministry of Ecology, Environment and Forest of Madagascar during 2006-2015. No specimen was taken from the wild during fieldwork; tortoises were only captured and handled for data recording during surveys.

\section{References}

Andrianandrasana, H. (2017) Testing the effectiveness of community-based conservation in conserving biodiversity, protecting ecosystem services, and improving human well-being in Madagascar. DPhil thesis, University of Oxford, Oxford, UK.

Avery, J. (2016) Anti-poaching pooches. Man's best friend plays a vital role in the war against poaching. Africa Geographic Magazine, 125. $\mathrm{Http}: / /$ magazine.africageographic.com/weekly/issue-125/ anti-poaching-pooches/ [accessed 6 June 2017].

Bennett, E.L. (2011) Another inconvenient truth: the failure of enforcement systems to save charismatic species. Oryx, 45, 476-479.

Biggs, D., Courchamp, F., Martin, R. \& Possingham, H.P. (2013) Legal trade of Africa's rhino horns. Science, 339, 1038-1039.

Buckland, S.T., Anderson, D.R., Burnham, K.P., LaAke, J.L., Borchers, D.L. \& Thomas, L. (2001) Introduction to Distance Sampling: Estimating Abundance of Biological Populations. Oxford University Press, Oxford, UK.

Challender, D.W.S. \& MacMillan, D.C. (2014) Poaching is more than an enforcement problem. Conservation Letters, 7, 484-494.

Cheung, S.N. \& Dudgeon, D. (2006) Quantifying the Asian turtle crisis: market surveys in southern China, 2000-2003. Aquatic Conservation: Marine and Freshwater Ecosystems, 16, 751-770.

CITES (2017) Convention on International Trade in Endangered Species of Wild Fauna and Flora. Appendices I, II and III. Http:// cites.org/eng/app/appendices.php [accessed 18 March 2017].

Curl, D.A. (1986) The rarest tortoise on earth. Oryx, 20, 35-39.

Curl, D.A., Scoones, I.C., Guy, M.K. \& Rakotoarisoa, G. (1985) The Madagascar tortoise Geochelone yniphora: current status and distribution. Biological Conservation, 34, 35-54.

D'Cruze, N. \& Macdonald, D.W. (2016) A review of global trends in CITES live wildlife confiscations. Nature Conservation, 15, 47-63.

Durbin, J., Rajafetra, V., Reid, D. \& Razandrizanakanirina, D. (1996) Local people and project Angonoka - Conservation of the ploughshare tortoise in north-western Madagascar. Oryx, 30, 113-120.

Gibbons, P. (2015) Ploughshare Tortoise Trafficking Update. Turtle Conservancy, Ojai, USA. Https://www.turtleconservancy.org/news/ 
2015/ploughshare-tortoise-trafficking-update [accessed 18 March 2016].

Gore, M.L., Ratsimbazafy, J. \& Lute, M.L. (2013) Rethinking corruption in conservation crime: insights from Madagascar. Conservation Letters, 6, 430-438.

Hall, R.J., Milner-Gulland, E.J. \& Courchamp, F. (2008) Endangering the endangered: the effect of perceived rarity on species extinction. Conservation Letters, 1, 75-81.

Hinsley, A., Lee, T.E., Harrison, J.R. \& Roberts, D.L. (2016) Estimating the extent and structure of trade in horticultural orchids via social media. Conservation Biology, 30, 1038-1047.

Horne, B.D., Poole, C.M. \& Walde, A.D. (2012) Conservation of Asian tortoises and freshwater turtles: setting priorities for the next ten years. Recommendations and Conclusions from the Workshop in Singapore, February 21-24, 2011. Wildlife Conservation Society, Singapore.

Jenkins, M.D. (1995) Tortoises and Freshwater Turtles: The Trade in Southeast Asia. TRAFFIC International, Cambridge, UK.

JuviK, J.O., Andrianarivo, A.J. \& BlanC, C.P. (1981) The ecology and status of Geochelone yniphora: A critically endangered tortoise in northwestern Madagascar. Biological Conservation, 19, 297-316.

Juvik, J.O. \& BlanC, C.P. (1974) The Angonoka of Cape Sada. Animals, 16, 148-153.

Kiester, A.R., Mandimbihasina, A.R., Lewis, R.E., Goode, E.V., Juvik, J.O., Young, R. \& Blanck, T. (2013) Conservation of the Angonoka (Ploughshare tortoise) Astrochelys yniphora. Chelonian Research Monographs, 6, 162-170.

Lawson, K. \& Vines, A. (2014) Global Impact of the IWT - The Costs of Crime, Insecurity and Institutional Erosion. Chatham House, London, UK.

Leuteritz, T. \& Pedrono, M. (Madagascar Tortoise and Freshwater Turtle Red List Workshop) (2008) Astrochelys yniphora. The IUCN Red List of Threatened Species 2008. Http://dx.doi.org/10.2305/ IUCN.UK.2008.RLTS.T9016A12950950.en.

Leuteritz, T. \& Rioux Paquette, S. (Madagascar Tortoise and Freshwater Turtle Red List Workshop) (2008) Astrochelys radiata. The IUCN Red List of Threatened Species. Http://dx.doi.org/10.2305/ IUCN.UK.2008.RLTS.T9014A12950491.en.

Leuteritz, T. \& Walker, R. (2014) Pyxis arachnoides. The IUCN Red List of Threatened Species. Http://dx.doi.org/10.2305/IUCN.UK. 2014-1.RLTS.T19035A50987297.en.

Leuteritz, T., Randriamahazo, H. \& Lewis, R. (Madagascar Tortoise and Freshwater Turtle Red List Workshop) (2008) Pyxis planicauda. The IUCN Red List of Threatened Species. Http:// dx.doi.org/10.2305/IUCN.UK.2008.RLTS.T19036A878999o.en.

Leuteritz, T.E.J., Lamb, T. \& Limberaza, J.C. (2005). Distribution, status, and conservation of radiated tortoises (Geochelone radiata) in Madagascar. Biological Conservation, 124, 451-461.

Lyons, J.A. \& NAtusCh, J.D. (2013) Effects of consumer preferences for rarity on the harvest of wild populations within a species. Ecological Economics, 93, 278-283.

Mandimbihasina, A. \& Woolaver, L. (2014) The ploughshare tortoise Astrochelys yniphora. In Western Indian Ocean Tortoises Ecology: Diversity, Evolution, Conservation, Paleontology (ed. J. Gerlach), pp. 277-296. Siri Scientific Press, Manchester, UK.

Moreto, W.D. \& Lemieux, A.M. (2015) Poaching in Uganda: perspectives of law enforcement rangers. Deviant Behavior, 36, $853-873$

Morgan, J., \& Chng, S. (2017). Rising internet-based trade in the Critically Endangered ploughshare tortoise Astrochelys yniphora in Indonesia highlights need for improved enforcement of CITES. Oryx, https://doi.org/10.1017/So03060531700031X.
NAtusch, J.D. \& Lyons, J.A. (2012) Exploited for pets: the harvest and trade of amphibians and reptiles from Indonesian New Guinea. Biodiversity and Conservation, 21, 2899-2911.

Nijman, V. \& Shepherd, C.R. (2007) Trade in non-native, CITES-listed, wildlife in Asia, as exemplified by the trade in freshwater turtles and tortoises (Chelonidae) in Thailand. Contributions to Zoology, 76, 207-211.

Nijman, V. \& Shepherd, C.R. (2015) Analysis of a decade of trade of tortoises and freshwater turtles in Bangkok, Thailand. Biodiversity and Conservation, 24, 309-318.

Nijman, V., Shepherd, C.R., Mumpuni, Saunders, K.L. (2012). Over-exploitation and illegal trade of reptiles in Indonesia. Herpetological Journal, 22, 83-89.

Obbard, M.E., Stapleton, S., Middel, K.R., Thibault, I., Brodeur, V. \& Jutras, C. (2015) Estimating the abundance of the Southern Hudson Bay polar bear subpopulation with aerial surveys. Polar Biology, 38, 1713-1725.

O'Brien, S., et al. (2003) Decline of the Madagascar radiated tortoise Geochelone radiata due to overexploitation. Oryx, 37, 338-343.

O'Donoghue, P. \& Rutz, C. (2015) Real-time anti-poaching tags could help prevent imminent species extinctions. Journal of Applied Ecology, 53, 5-10.

Olmedo, A., Sharif, V. \& Milner-Gulland, E.J. (2017) Evaluating the design of behaviour change interventions: A case study of rhino horn in Viet Nam. Conservation Letters, 11, 1-9.

Pedrono, M. (200o) Gestion interactive entre les populations sauvages et captives: Stratégie de conservation de la tortue Astrochelys yniphora à Madagascar. $\mathrm{PhD}$ thesis, Université Pierre et Marie Curie, Paris, France.

Pedrono, M. (2008) The Tortoises and Turtles of Madagascar. Natural History Publications, Borneo.

Raghavan, R., Luz, S., Shepherd, C.R., Lewis, R., Gibbons, P. \& Goode, E. (2015) A case study of the ploughshare tortoise and the role zoos can play in conservation. TRAFFIC Bulletin, 27, 79-84.

Randriamalala, H. \& LiU, Z. (2010) Rosewood of Madagascar: between democracy and conservation. Madagascar Conservation \& Development, 5, 11-22.

Rosen, G.E. \& SMith, K.F. (2010) Summarizing the evidence on the international trade in illegal wildlife. EcoHealth, 7, 24-32.

Smith, L.L., Bourou, R., Mahatoly, J. \& Sibo, C. (1999a) Home range and microhabitat use in the Angonoka (Geochelone yniphora) in Madagascar. Chelonian Conservation and Biology, 3, 393-400.

Smith, L.L., Linehan, J.M., Stober, J.M., Elliott, M.J. \& Jensen, J.B. (2009) An evaluation of distance sampling for large-scale gopher tortoise surveys in Georgia, USA. Applied Herpetology, 6, $355-368$.

Smith, L.L., Reid, D., Bourou, R., Mahatoly, J. \& Sibo, C. (1999b) Status and distribution of the angonoka tortoise (Geochelone yniphora) of western Madagascar. Biological Conservation, 91, 23-33.

Swann, D.E., Averill-Murray, R.C. \& Schwalbe, C.R. (2002) Distance sampling for Sonoran desert tortoises. Journal of Wildlife Management, 66, 969-975.

Thomas, L., Buckland, S.T., Rexstad, E.A., LaAke, J.L., StrindberG, S., Hedley, S.L. et al. (2010) Distance software: design and analysis of distance sampling surveys for estimating population size. Journal of Applied Ecology, 47, 5-14.

TRAFFIC (2014) Seizures and prosecutions. TRAFFIC Bulletin, 16 (3) (March 1997)-26 (2) (October 2014).

TRAFFIC (2016) TRAFFIC's engagement on African rhinoceros conservation and the global trade in rhinoceros horn. Http://www. traffic.org/rhinos/ [accessed 24 November 2016]. 
Underwood, F.M., Burn, R.W. \& Milliken, T. (2013) Dissecting the illegal ivory trade: an analysis of ivory seizures data. PLOS ONE, 8, e76539.

Vaillant, L. \& Grandidier, G. (1910) Histoire Naturelle des Reptiles, Première Partie: Crocodiles et Tortues. In Histoire Physique Naturelle et Politique de Madagascar (eds A. Grandidier \& G. Grandidier), vol. 17, pp. 1-86. Imprimerie nationale, Paris, France.

Veríssimo, D., Challender, D.W.S. \& Nijman, V. (2012) Wildlife trade in Asia: start with the consumer. Asian Journal of Conservation Biology, 2, 49-50.

Walker, R.C. \& Rafeliarisoa, T.H. (2012) Status of the relict population of the Critically Endangered Madagascar spider tortoise Pyxis arachnoides. Oryx, 46, 457-463.

WALKER, R.C.J. (2012) The internet based trade in Madagascar's critically endangered tortoise species: A preliminary study identifying the conservation threats. Testudo, 7, 3-13.
WALLIS, D. (2009). Evaluating the short-term success of a reintroduction of the Critically Endangered ploughshare tortoise, Astrochelys yniphora. MSc thesis, Imperial College London, London, UK.

WYLER, L.S. \& SHeikh, P.A. (2013) International Illegal Trade in Wildlife: Threats and U.S. Policy. CRS report for Congress, Damascus, USA.

Young, R.P., Volahy, A.T., Bourou, R., Lewis, R., Durbin, J. \& FA, J.E. (2008) Estimating the population of the Endangered flat-tailed tortoise Pyxis planicauda in the deciduous, dry forest of western Madagascar: a monitoring baseline. Oryx, 42, 252-258.

ZHOU, Z. \& JIANG, Z. (2004) International trade status and crisis for snake species in China. Conservation Biology, 18, 1386-1394.

Zylstra, E.R., SteidL, R.J. \& SwANn, D.E. (2010) Evaluating survey methods for monitoring a rare vertebrate, the sonoran desert tortoise. Journal of Wildlife Management, 74, 1311-1318. 